\title{
RANCANG BANGUN SORTIR DAN HITUNG LEMBAR KERTAS A4 OTOMATIS MENGGUNAKAN SENSOR LDR DAN APLIKASI BLYNK
}

\author{
Hanna Alifia Putri Riyanto ${ }^{1}$
}

Teknik Elektronika, Politeknik Negeri Cilacap, Cilacap, Indonesia

email: hannaalifiaputri11@ gmail.com ${ }^{1}$

\begin{abstract}
The sorter and counting process of sheets paper still manually in several companies. So, in this study designed a tool that can automatically sorter and count paper based of paper quality. Paper is said to be suitable for use when there are no stains on a clean white sheet of paper, and on the other hand, the paper is said to be unfit for use when the paper is stained with ink. In this research, the LDR sensor functions as a sorting sensor, the resistance value received on the paper will be calculated. When the LDR captures a light resistance value less than 75 , the paper will be categorized as a good paper quality, and vice versa when the LDR captures a light resistance of more than 75, the paper will be categorized as a dirty paper quality. next process the paper will be pushed to each shelf, this process involves a photodiode as a paper counter. When the paper passes through the photodiode, the process will be counted as one cycle or one paper. Furthermore, the paper will be separated into different racks according to the paper quality using the MG955 servo motor. In the servo motor test, the angular movement is $10^{\circ}$ for good paper racks and $60^{\circ}$ for dirty paper racks. After going through the process, the overall results of the paper data will be sent to NodeMCU ESP8266 and displayed on the blynk application.
\end{abstract}

Keywords: LDR, Photodioda, Motor Servo, NodeMCU ESP8266.

\begin{abstract}
Abstrak
Proses sortir dan hitung lembar kertas umumnya masih dilakukan secara manual di beberapa perusahaan. Sehingga dalam penelitian ini merancang sebuah alat yang dapat melakukan proses sortir dan hitung kertas secara otomatis berdasarkan kualitas kertas. Kertas dikatakan layak pakai ketika dalam lembaran kertas putih bersih tidak ada noda, dan sebaliknya kertas dikatakan tidak layak pakai ketika dalam lembaran kertas tersebut terdapat noda pekat oleh tinta. Pada penelitian ini sensor LDR digunakan sebagai sensor sortir, nilai resistansi yang diterima pada pembacaan kertas akan diperhitungkan. Ketika LDR menangkap nilai resistansi cahaya kurang dari 75 maka kertas akan dikategorikan sebagai kertas kualitas baik, dan sebaliknya ketika LDR menangkap resistansi cahaya lebih dari 75 maka kertas akan dikategorikan sebagai kertas kualitas kotor. Proses selanjutnya kertas akan didorong ke masing - masing rak, proses ini melibatkan photodioda sebagai penghitung kertas. Ketika kertas melewati photodioda maka proses tersebut akan terhitung satu siklus atau satu kertas. Selanjutnya kertas akan dipisahkan dengan rak yang berbeda sesuai dengan kualitas kertas menggunakan motor servo MG955 dalam pengujian motor servo menghasilkan pergerakan sudut $10^{\circ}$ untuk rak kertas bersih dan $60^{\circ}$ untuk rak kertas kotor. Setelah melewati proses tersebut maka hasil keseluruhan data kertas akan dikirimkan ke NodeMCU ESP8266 dan ditampilkan pada aplikasi blynk.
\end{abstract}

Kata Kunci: LDR, Motor Servo, NodeMCU ESP8266, Photodioda.

\section{PENDAHULUAN}

Pada proses produksi kertas di salah satu perusahaan menghasilkan produk kertas tidak layak pakai yang melebihi target perusahaan sebesar 5\% per hari dalam proses produksi. Presentase produk kertas tidak layak pakai yang dihasilkan bersifat fluktuatif setiap harinya. Hal ini dapat dilihat dari data hasil produksi selama 3 bulan terakhir dalam kurun waktu bulan Oktober - Desember 2017. Pada bulan Oktober terdapat 19 hari dimana presentase produk kertas tidak layak pakai melebihi target. Pada bulan November terdapat 15 hari yang melebihi target. Sedangkan pada bulan Desember terdapat 13 hari yang melebihi target. Jika diakumulasikan pada 3 bulan terakhir terdapat 47 hari dimana proporsi produk kertas tidak layak pakai melebihi target.[1]

Dengan meningkatnya produksi tingkat kertas tidak layak pakai ini, proses sortir dan penghitung kertas sangatlah berperan aktif dalam pemilihan baik buruknya suatu kertas dikarenakan proses pemilihan kualitas kertas di beberapa perusahaan kurang akurat karena masih dilakukan secara manual oleh manusia, seperti yang kita ketahui manusia memiki keterbatasan. Diantaranya keterbatasan dalam menilai komposisi bercak karena adanya noda yang sangat bergantung pada persepsi atau subjektifitas, sehingga tidak konsisten dan timbul kesalahan - kesalahan (human error) yang mengurangi tingkat efektifitas dan efesiensi. Akibatnya waktu pengerjaan tugas menjadi lebih lama sehingga berdampak pada menurunnya produktivitas perusahaan.

Untuk mengatasi hal ini, dibutuhkan suatu sistem proses sortir dan hitung kertas otomatis berdasarkan kualitas kertas dengan tingkat layak atau tidaknya suatu kertas secara otomatis dan lebih cepat. Kertas dikatakan layak pakai ketika dalam lembaran kertas putih bersih tidak ada noda, dan sebaliknya kertas dikatakan tidak layak pakai ketika dalam lembaran kertas tersebut terdapat noda. Sensor LDR (Light Dependent Resistor) berfungsi sebagai sensor sortir. Sensor sortir ini lebih mudah dibuat karena LDR banyak tersedia dipasaran. Selain itu, LDR juga merupakan jenis resistor yang nilai resistansinya digunakan sebagai sensor kejernihan dalam menyortir kualitas kertas baik kertas tidak layak pakai maupun layak pakai. Hasil sortir tersebut nantinya akan dipisahkan dengan rak yang berbeda menggunakan motor servo dan pemantauan data yang dihasilkan akan dikirimkan melalui aplikasi blynk.

Dengan adanya sistem ini diharapkan proses sortir dan penghitung kertas otomatis ini dapat membantu operator dalam proses menyortir, menghitung, memperoleh dan memantau data kertas melalui aplikasi blynk yang terdapat di handphone operator. 


\section{KAJIAN PUSTAKA}

A. Arduino Mega 2560

Arduino Mega 2560 merupakan papan pengembangan mikrokontroller yang berbasis Arduino menggunakan chip ATmega2560. Arduino Mega 2560 berfungsi sebagai pengendali yang mengatur jalannya proses kerja pada rangkaian elektronik.

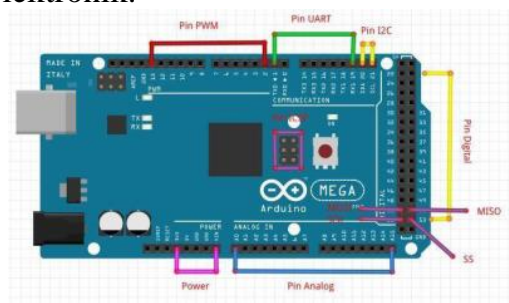

Gbr 1. Arduino Mega 2560

Arduino Mega 2560 memiliki pin I/O sejumlah 54 buah digital I/O pin (15 pin diantaranya adalah PWM), 16 pin analog input, 4 pin UART (serial port hardware). Arduino Mega 2560 telah dilengkapi dengan sebuah oscillator 16 Mhz, sebuah port USB, power jack DC, ICSP header, dan tombol reset.[2]

\section{B. NodeMCU ESP8266}

NodeMCU ESP8266 merupakan Modul yang menyerupai arduino namun terdapat perbedaan yakni dapat terhubung ke internet. NodeMCU ESP8266 dapat

terhubung ke internet karena didalamnya terdapat sistem onchip yang telah terintegrasi sehingga dapat lebih mudah diakses dengan mikrokontroller lainnya melalui komunikasi

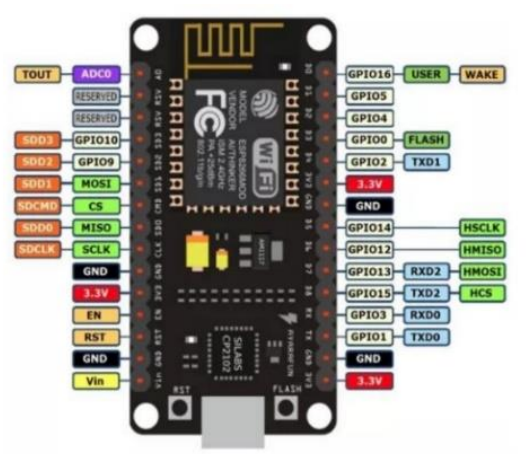
serial.[3]

Gbr 2. NodeMCU ESP8266

\section{Blynk}

Blynk merupakan sebuah platform baru yang dapat membangun interface untuk mengendalikan dan memantau proyek hardware dari iOS dan perangkat Android.[4]

Blynk dirancang untuk membuat remote control dan data sensor membaca dari perangkat ESP8266 ataupun Arduino dengan sangat cepat dan mudah

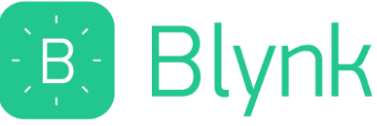

Gbr 3. Aplikasi Blynk

\section{D. $\quad$ Light Dependent Resistor (LDR)}

Light Dependent Resistor (LDR) digunakan sebagai sensor utama dalam tugas akhir ini, LDR adalah suatu bentuk komponen yang mempunyai perubahan resistansi yang besarnya tergantung pada cahaya.

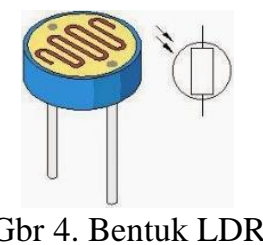

LDR dapat dikatakan bahwa resistansi mereka berbanding terbalik dengan jumlah cahaya yang mereka terima. Oleh karena itu, LDR adalah fotosensor yang paling disukai, di mana intensitas cahaya yang diharapkan bervariasi, dibandingkan dengan intensitas cahaya yang ditetapkan. Waktu respons LDR sedang dan juga menguntungkan, karena merupakan resistor dua arah.[5]

\section{E. LED (Light Emitting Diode)}

LED digunakan untuk proses pencahayaan pada sensor LDR sehingga pantulan cahaya dapat dideteksi oleh sensor LDR. Pada dasarnya LED merupakan komponen elektronika yang terbuat dari bahan semi konduktor jenis dioda yang mampu memancarkan cahaya.

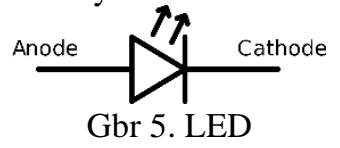

Cara Kerja LED yaitu akan memancarkan cahaya apabila dialiri tegangan maju (bias forward) dari anoda (+) ke katoda (-). [6]

\section{F. Photodioda}

Prinsip kerja photodiode sama seperti sensor LDR, mengubah besaran cahaya yang diterima sensor menjadi perubahan konduktansi (kemampuan suatu benda menghantarkan arus listrik dari suatu bahan). Hanya saja, photodioda digunakan dalam bias balik yaitu mati saat intensitas cahaya terlampaui dan menyala pada saat intensitas cahaya memadai karena fotodioda memiliki dua tingkat keluaran secara spesifik. Dari aksi fotodioda dapat dikatakan bersifat searah.

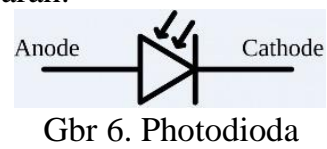

Dalam tugas akhir ini, Photodiode digunakan sebagai pendeteksi keberadaan kertas menghitung jumlah hasil keseluruhan kertas yang disortir, dan dipisahkan kembali sesuai dengan hasil sortir yaitu kertas bersih dan kertas kotor.

\section{G. LED Infrared}

LED Infrared merupakan salah satu LED (Light Emitting Diode) yang dapat memancarkan cahaya yang tidak kasat mata.

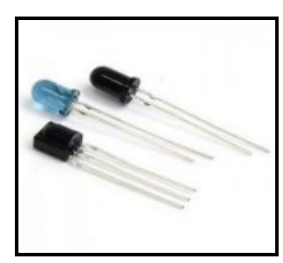

Gbr 7. LED Infrared 
Cahaya infrared tidak mudah terkontaminasi atau teresonan dengan cahaya lain, sehingga dapat digunakan baik siang maupun malam.[7]

\section{H. Power Supply (Catu Daya)}

Power Supply merupakan sumber daya listrik atau sebuah Perangkat yang dapat memasok listrik atau jenis energi output beban. Pada masing - masing perangkat elektronika mestinya di catu oleh suplai arus searah DC (Direct Current) yang stabil agar dapat bekerja dengan baik.[8]

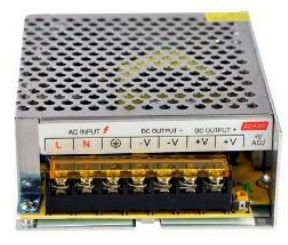

Gbr 8. Power Supply

Power Supply yang digunakan pada tugas akhir ini, Power Supply 12 V/ 10A dengan adaptor AC 220v ke DC 12 $\mathrm{v}$, power supply ini cocok untuk lampu LED, LED Strip, Motor DC, dst.

\section{Motor DC}

Motor DC merupakan sebuah perangkat yang berfungsi mengubah energi listrik menjadi energi mekanik. Oleh karena itu, motor ini membutuhkan suplai berupa tegangan listrik agar bisa bekerja.[10]

Motor DC tersusun dari dua bagian yaitu bagian dian (stator) dan bagian bergerak (rotor). Stator motor arus searah adalah badan motor atau kutub magnet (sikat - sikat), sedangkan yang termasuk rotor adalah jangkar lilitannya.[11]

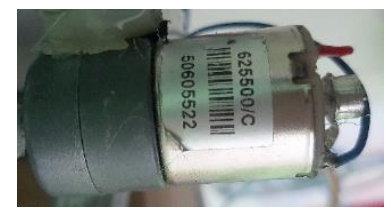

Gbr9. Motor DC

Motor DC yang digunakan pada Tugas Akhir ini memnggunakan tipe 625500/c yang memiliki range tegangan $6-12 \mathrm{~V}$. Untuk menggerakannya dengan konsumsi daya $0,005 \mathrm{~A}$ dan memiliki $32-64 \mathrm{Rpm}$.

\section{J. Motor Servo}

Motor Servo merupakan sebuah perangkat atau aktuator putar (motor) yang dirancang dengan sistem kontrol umpan balik (loop tertutup) sehinggga dapat disetup atau diatur untuk menentukan dan memastikan sudut dari poros motor servo.[12]

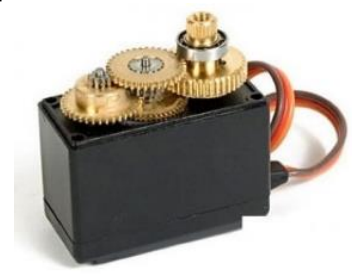

Gbr 10. Motor Servo
Dalam motor servo terdapat potensiometer sebagai sensor posisi yang dihubungkan dengan output shaft untuk mengetahui posisi aktual shaft. Dan motor dc, motor dc akn berputar, sehingga output shaft juga berputar dan sekaligus memutar potensiometer.[13]

Motor Servo 955 yang digunakan pada alat ini, memiliki datasheet sebagai berikut: Berat 55g, dimensi 40,7 x 19.7 x $42.9 \mathrm{~mm}$, torsi maksimal $8,5 \mathrm{~kg}$ (4.8V) sampai $10 \mathrm{~kg}(6 \mathrm{~V})$ dan bekerja didalam tegangan $4.8 \mathrm{~V}$ sampai $7.2 \mathrm{~V}$. [14]

\section{K. Relay $5 \mathrm{~V}$}

Relay merupakan komponen elektronika yang dapat bekerja berdasarkan induksi elektromagnet. Ketika suatu kawat penghantar (coil) dialiri arus akan timbul medan magnet yang mengelilingi penghantar tersebut. Medan magnet ini yang dimanfaatkan untuk menarik kontak saklar. Oleh karena itu, komponen utama dari relay adalah coil dan kontak.

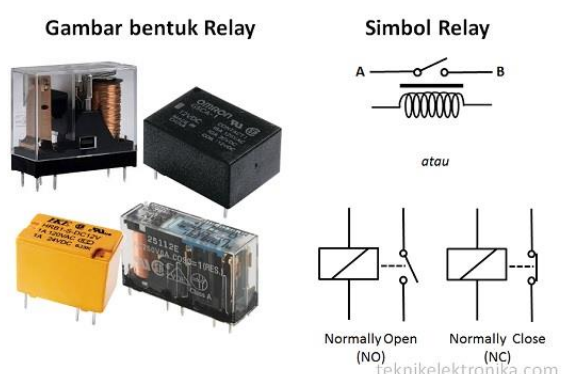

Gbr 12. Relay5V

Kontak relay terdiri dari 2 (dua) jenis: yaitu Normally Close (NC) dan Normally Open (NO). Ketika kontak NO dalam kondisi membuka maka relay tidak dialiri arus listrik. Sedangkan ketika NC berada dalam keadaan menutup maka relay tidak dialiri arus listrik.[15]

\section{A. Blok Diagram}

\section{METODE}

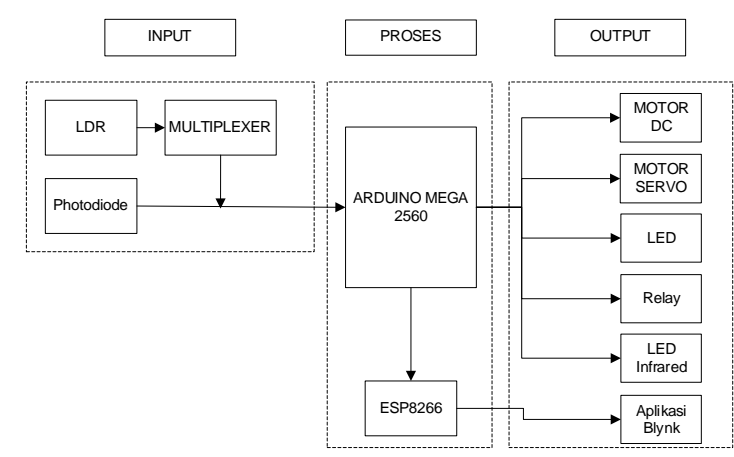

Gbr 13. Blok Diagram

Pada gambar diatas dapat dijelaskan bahwa terdapat dua sistem proses yaitu proses pertama terdapat arduino mega 2560, Arduino Mega 2560 hanya memiliki 16 pin analog input, sehingga akan membutuhkan 2 buah multiplexer sebagai pengganti input atau masukan dari 26 buah sensor LDR. Dan proses kedua terdapat NodeMCU ESP8266 sebagai receiver atau penerima data dari LDR dan Photodioda yang hasilnya akan ditampilkan di aplikasi Blynk. 


\section{B. Flowchart Sistem}

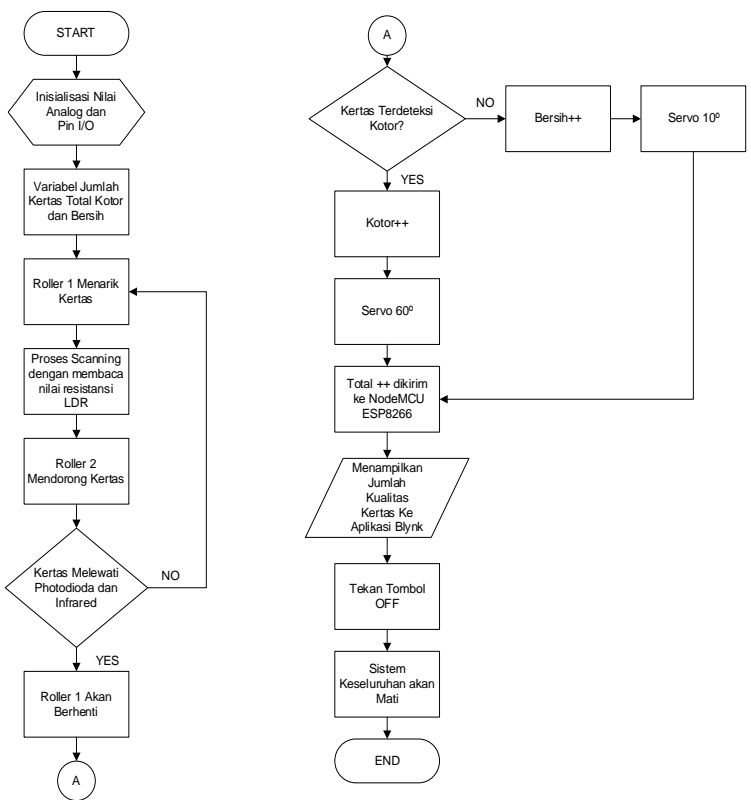

Gbr 14. Flowchart Sistem

Gambar diatas menjelaskan alur program sistem dari Rancang Bangun Penyortir Dan Penghitung Lembar Kertas A4 Otomatis Menggunakan sensor LDR dan Aplikasi Blynk, pada saat kontroller dinyalakan, akan dilakukan proses inisialisasi pada port $\mathrm{I} / \mathrm{O}$, kemudian nilai analog yang akan terbaca dari LDR akan menjadi nilai acuan untuk perhitungan nilai dari kekotoran kertas. Proses selanjutnya perlu dibuat variabel global untuk menyimpan nilai dari jumlah kertas kotor, bersih dan total keseluruhan kertas yang telah disortir. Roller 1 akan menarik kertas input dan akan mendorong ke proses scanning menggunakan sensor LDR. Pada saat kontroller dinyalakan posisi awal motor servo pada sudut $10^{\circ}$. Selanjutnya roller 1 akan mati saat kertas terdeteksi pada roller 2, hal ini dikarenakan adanya pendeteksian yang dilakukan menggunakan photodiode dan infrared LED yang dipantulkan pada kertas. Selama kertas belum terdeteksi pada roller kedua, maka kondisi demikian dianggap kertas belum melewati proses scanning sehingga roller 1 akan terus berjalan dan LDR akan melakukan scanning. Saat terdeteksi kertas kotor, LDR akan berhenti scanning dan servo akan diposisikan pada posisi $60^{\circ}$, dan sebaliknya saat kertas terdeteksi bersih, LDR juga akan berhenti scanning dan servo diposisikan seperti semula yaitu $10^{\circ}$.

Setelah kertas tidak terdeteksi pada roller 2, akan mengindikasikan kertas telah berada pada posisi terpisah dan proses scanning dan pemisahan satu buah kertas selesai. Selanjutnya variabel total kertas akan ditambah satu lalu data kotor, bersih, dan total keseluruhan kertas yang telah melakukan scanning akan dikirim ke blynk melalui nodemcu

\section{Perancangan Proses Scanning Kualitas Kertas dengan LDR (Light Dependent Resistor)}

Sensor utama yang digunakan pada alat ini adalah sensor LDR. LDR digunakan untuk menangkap cahaya yang dipancarkan oleh LED dan dapat mendeteksi kondisi kertas baik dan buruk. Kertas dikatakan baik jika dikertas tidak terdapat noda atau kotoran sedangkan kertas dikatakan buruk jika dikertas terdapat coretan, kotoran, dan noda.

Konfigurasi koneksi antara Sensor LDR dengan Arduino Uno dapat dilihat pada Gambar 3.3.

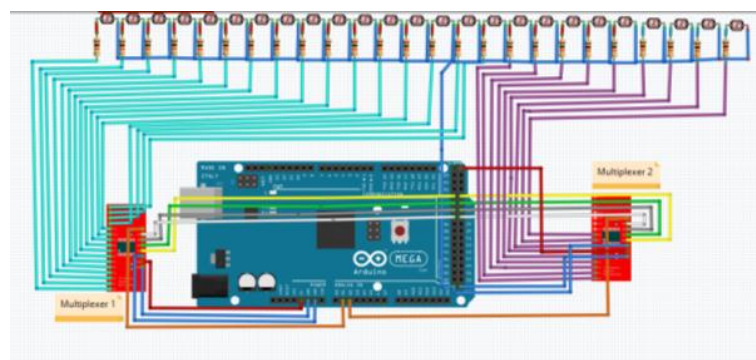

Gbr 15. Rangkaian LDR

Keterangan :

1. Kabel warna Merah : VCC ke VCC

2. Kabel warna Biru : GND ke GND

3. Kabel warna Kuning : S0 Multiplexer1 ke pin 28

4. Kabel warna Hijau : S1 Multiplexer1 ke pin 30

5. Kabel warna Grey : S2 Multiplexer1 ke pin 32

6. Kabel warna Putih : S3 Multiplexer1 ke pin 34

7. Kabel warna Oren : SIG Multiplexer1 ke pin A1

8. Kabel warna Kuning : S0 Multiplexer2 ke pin 29

9. Kabel warna Hijau : S1 Multiplexer2 ke pin 31

10. Kabel warna Grey : S2 Multiplexer2 ke pin 33

11. Kabel warna Putih : S3 Multiplexer2 ke pin 35

12. Kabel warna Oren : SIG Multiplexer2 ke pinA2

13. Kabel warna Tosca : C0-C15 Multiplexer1 ke LDR

14. Kabel warna Ungu : C0-C15 Multiplexer2 ke LDR

Pada gmbr15 diatas menggunakan 26 sensor LDR dikarenakan lebar kertas HVS A4 adalah $21 \mathrm{~cm}$, dan jarak antar kaki 1 sensor LDR adalah 1,3cm. Sehingga dengan menggunakan 26 sensor LDR dapat mendeteksi baik atau buruknya dari lebar kertas HVS A4 dengan baik.

\section{Perancangan Rangkaian MainBoard Secara Keseluruhan}

Pada perancangan rangkaian mainboard berisi pin header yang menghubungkan sensor dan akuator ke pin yang terdapat di Arduino mulai dari sensor LDR, sensor Photodiode, servo dan led.

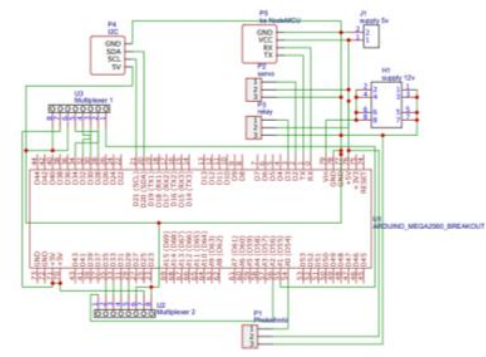

Gbr16. Rangkaian Mainboard

Gambar diatas menunjukan beberapa blok header pada mainboard, pertama pada sebelah kiri atas ada blok rangkaian Multiplexer 1 di mana terdapat 8 header untuk 13 sensor LDR, power sensor LDR diambil dari VCC/ Sumber Ardruino 5v. Dan rangkaian Multiplexer 1 dihubungkan ke 
pin A1, 28, 30, 32, dan 34 Arduino. Kedua di sebelah rangkaian sensor $L D R$ terdapat beberapa rangkaian relay, Node MCU, dan Motor Servo. Pertama untuk rangkaian relay 1 channel dihubungkan langsung ke supply 5v, Gnd dan pin 3 Arduino. Kedua Node MCU menggunakan 4 header pin Arduino yaitu VCC 5v, Gnd, Tx 1, dan Rx 0. Dan ketiga untuk Servo menggunakan 3 pin untuk disambungkan ke Arduino, yaitu VCC 5v, GND dan pin 2.

Bagian kanan bawah terdapat rangkaian photodiode yang berguna untuk mendeteksi keberadaan kertas setelah melewati proses sortir dan hitung. Rangkaian ini membutuhkan 3 pin header arduino yaitu, VCC 5v, Gnd dan A0. Dan bagian kiri bawah terdapat rangkaian multiplexer 2 yang membutuhkan 8 pin header untuk 13 sensor LDR. Rangkaian Multiplexer 2 dihubungkan ke pin 29, 31, 33, dan 35 Arduino.

\section{E. Perancangan Desain Mekanik}

Pada Perancangan Desain Mekanik terdapat beberapa bagian yaitu input kertas (kertas masukan), roller pendorong, penggerak motor untuk menyortir kertas, dan rak output kertas.

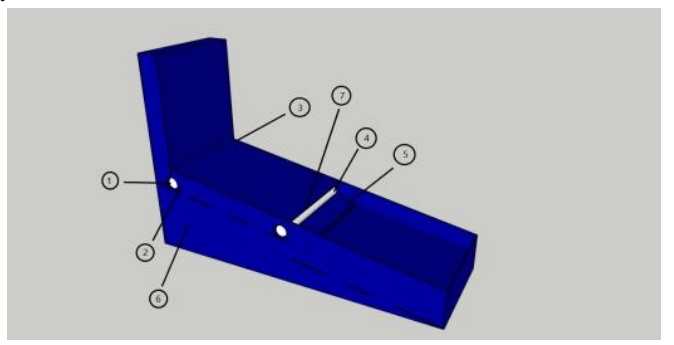

Gbr17. Desain Mekanik

Pada gambar diatas dijelaskan bahwa bahan-bahan yang dipakai adalah akrilik, silinder, karet penarik kertas printer, 4 motor DC dan motor servo. Akrilik yang digunakan adalah akrilik dengan tebal $2 \mathrm{~mm}$, kemudian roller terbuat dari 3D printer dengan diameter $2,3 \mathrm{~cm}$. Digunakannya ukuran, karena menyesuaikan dengan ukuran karet penarik kertas dan mencegah terjadinya kertas double. Kemudian akrilik untuk wadah kertas disesuaikan dengan kertas ukuran A4, agar kertas tidak berantakan. Kemudian motor DC dengan maksimal kecepatan sebesar 120 RPM. Motor yang digunakan pada alat ini tidak di atur kecepatannya atau tidak menggunakan dimmer karena maksimal kecepatan motor sudah cukup. Motor DC diletakkan didalam roller. Motor DC tersebut digunakan untuk memutar roller, sehingga roller tersebut dapat menarik kertas dan menjalankan kertas ke tempat sortir. Sortir kertas menggunakan Motor Servo untuk membawa kertas ke rack atau wadah kertas dari hasil akhir penyortiran.

\section{F. Perancangan Aplikasi Blynk}

Perancangan pada aplikasi Blynk dimulai dengan membuka apalikasi blynk yang sudah diinstal kemudian login menggunkan akun e-mail dan password yang sudah ditentukan. Lalu membuat project baru dengan cara memilih perangkat/komponen yang akan dihubungkan dengan aplikasi blynk kemudia atur widget yang dibutuhkan seperti pada Gambar dibawah ini:

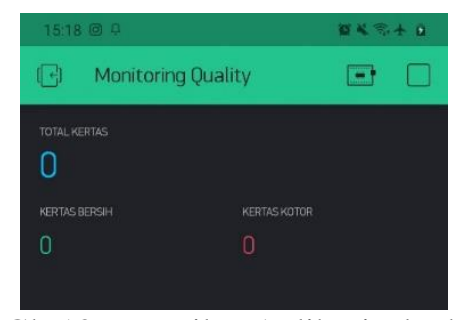

Gbr18. Tampilan Aplikasi Blynk

Pada Gambar diatas merupakan tampilan aplikasi blynk yang akan digunakan. Terdapat widget value display untuk monitoring banyaknya kertas yang telah disortir berupa kertas kotor dan kertas baik.

\section{HASIL DAN PEMBAHASAN}

A. Pengujian Sortir Kualitas Kertas dengan Sensor LDR

Pada saat sensor $L D R$ terlewati kertas, maka akan ditangkap dan dibaca nilai resistansinya. Ketika nilai resistansi rendah akan dikatakan memiliki nilai minimal yaitu 0 dan kertas tersebut akan terbaca "bersih atau tidak ada noda" dan sebaliknya, ketika kertas memiliki resistansi yang tinggi akan dikatakan memiliki nilai maksimal sampai dengan 1024, dan kertas tersebut akan terbaca "kotor atau terdapat noda".

Pada pengujian deteksi kualitas kertas dengan sensor $L D R$, akan dilakukan pengujian dengan cara melihat nilai hasil pada arduino. Hasil pengukuran dapat dillihat pada Tabel 1 dibawah ini:

Tbl 1. Pengujian Nilai Pada Sensor $L D R$

\begin{tabular}{cccc}
\hline No & $\begin{array}{c}\text { Deteksi } \\
\text { Kertas }\end{array}$ & $\begin{array}{c}\text { Nilai Hasil } \\
\text { Akhir } \\
\text { Sensor }\end{array}$ & $\begin{array}{c}\text { Output } \\
\text { Digital }\end{array}$ \\
\hline 1 & Bersih & 63 & 0 \\
\hline 2 & Kotor $1 \mathrm{~cm}$ & 108 & 1 \\
\hline 3 & Bersih & 55 & 0 \\
\hline 4 & Kotor $2 \mathrm{~cm}$ & 78 & 1 \\
\hline 5 & Bersih & 52 & 0 \\
\hline 6 & Kotor $3 \mathrm{~cm}$ & 81 & 1 \\
\hline 7 & Bersih & 41 & 0 \\
\hline 8 & Kotor $4 \mathrm{~cm}$ & 101 & 1 \\
\hline 9 & Bersih & 67 & 0 \\
\hline 10 & Kotor $5 \mathrm{~cm}$ & 87 & 1 \\
\hline
\end{tabular}

Pada Tabel diatas Nilai Hasil diambil dari (Nilai ratarata LDR - nilai minimal) - (nilai maksimal LDR - nilai rata-rata LDR). Sehingga akan mendapatkan nilai yang sesuai dengan nilai set point yang diatur. suatu kertas apakah kertas tersebut kotor dan tidak layak pakai ataukah bersih dan layak pakai. Pengujian kualitas kertas menggunakan sensor LDR sebanyak 10 kertas. Pengujian kertas bersih dibuktikan pada Gambar dibawah ini: 


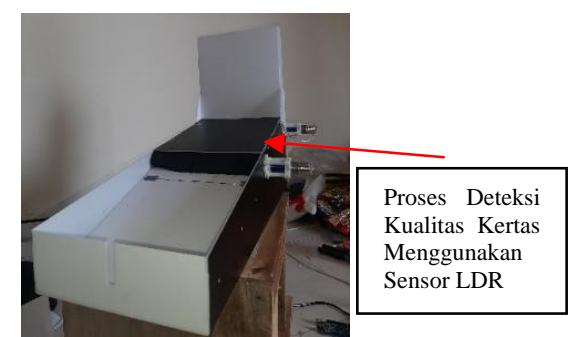

Gbr18. Pengujian Sortir Sensor LDR

Gambar 18 merupakan pembuktian pengujian sortir menggunakan sensor LDR dengan dipancari lampu LED. Pengujian tersebut bertujuan untuk mendapatkan nilai resistansi dari LDR. Ketika nilai resistansi LDR dibawah 75 maka kertas akan dianggap bersih dan sebaliknya ketika nilai resistansi LDR diatas 75 maka kertas akan dianggap kotor.

\section{B. Pengujian Aktuator Kertas Perlembar dengan Motor Servo MG955}

Sebelum ke pengujian aktuator kertas perlembar dengan motor servo, perlu dilakukan pengujian posisi putaran motor servo agar dapat bergerak sesuai dengan posisi rak yang akan menjadi tempat kertas. Sehingga kertas dapat dipisahkan sesuai dengan gradenya. Hasil pengujian posisi motor servo dapat dilihat dari Tabel 2 dibawah ini:

Tbl 2. Pengujian Posisi Motor Servo

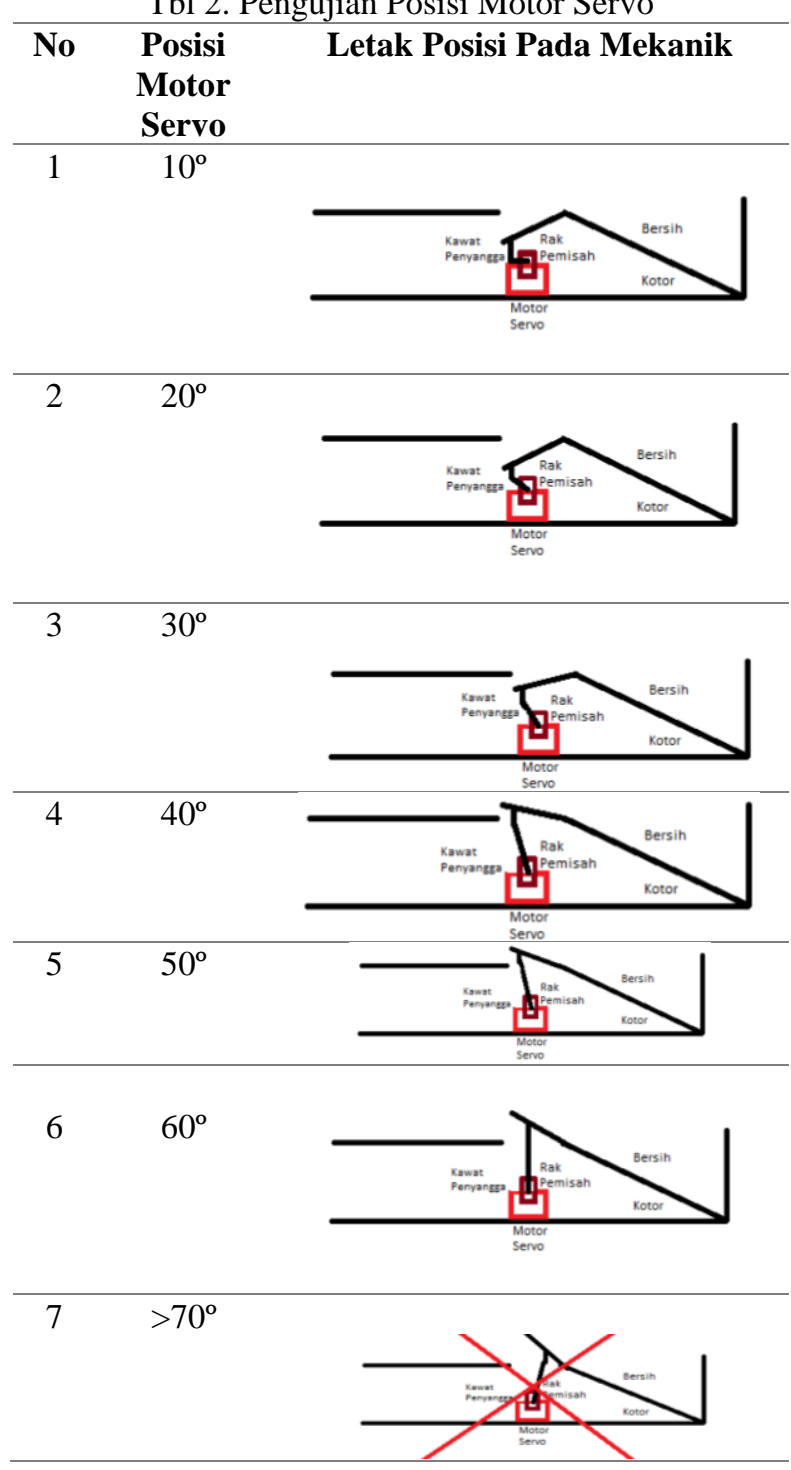

Dapat disimpulkan dari Tabel diatas posisi motor servo yang baik untuk grade kualitas kertas bersih adalah $10^{\circ}$ dikarenakan posisi tersebut dapat menempatkan kertas dengan baik setelah didorong dari roller kedua, sedangkan posisi motor servo yang baik untuk grade kualitas kertas kotor adalah $60^{\circ}$ karena pada posisi tersebut kertas yang telah didorong oleh roller kedua akan jatuh kerak bawah dan tidak menyangkut pada sisi kanan dan kiri mekanik. Posisi motor servo $60^{\circ}$ juga merupakan posisi akhir dari pergerakan motor servo, dikarenakan ketika motor servo berubah sudutnya $>70^{\circ}$ maka mekanik pada pemisah kertas akan rusak karena servo akan putar balik ke balakang.

Selanjutnya terdapat pengujian aktuator kertas perlembar. Pengujian ini bertujuan untuk mengetahui kertas yang dapat dipisahkan sesuai dengan grade masing - masing kualitas kertas. Pemisah kertas pada alat ini menggunakan motor servo MG 955. Hasil pengujian aktuator kertas dapat dilihat pada Tabel 3 dibawah ini:

\begin{tabular}{ccc}
\multirow{2}{*}{ Tbl 3. Pengujian Aktuator Kertas Perlembar } \\
\hline No & $\begin{array}{c}\text { Jenis Kualitas } \\
\text { Kertas }\end{array}$ & \multicolumn{2}{c}{ Terpisahkan } \\
\cline { 2 - 3 } & Ya & Tidak \\
\hline 1 & Bersih & $\sqrt{ }$ \\
\hline 2 & Kotor & $\sqrt{ }$ \\
\hline 3 & Bersih & $\sqrt{ }$ \\
\hline 4 & Kotor & $\sqrt{ }$ \\
\hline 5 & Bersih & $\sqrt{ }$ \\
\hline 6 & Kotor & $\sqrt{ }$ \\
\hline 7 & Bersih & $\sqrt{ }$ \\
\hline 8 & Kotor & $\sqrt{ }$ \\
\hline 9 & Bersih & $\sqrt{ }$ \\
\hline 10 & Kotor & $\sqrt{ }$ \\
\hline
\end{tabular}

Dari hasil pengujian aktuator kertas menurut jenis kualitas kertas, dapat dijelaskan bahwa kertas bersih atau layak pakai dan kertas kotor atau tidak layak pakai dapat disortir oleh alat ini menggunakan motor servo MG955. Pengujian sortir atau pemisah kertas ke masing - masing rak dapat dilihat pada Gambar 4.2:

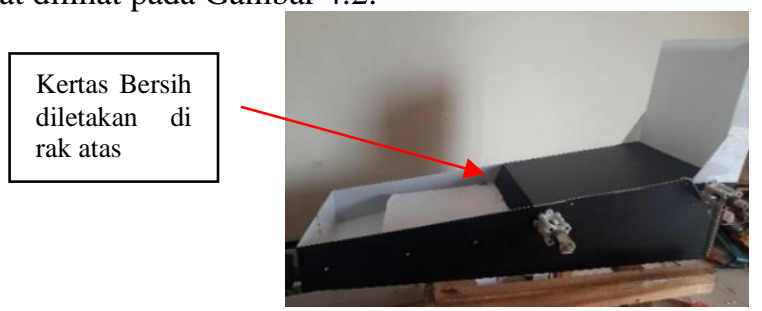

Gbr19. Pemisah Kertas Bersih

Pada gambar tersebut merupakan proses pengujian sortir atau pemisah kertas bersih. Setelah kertas melewati proses deteksi kualitas kertas, maka kertas akan didorong menuju rak sesuai dengan grade kertas. Ketika grade kertas bersih, maka servo akan menggerakan posisi $10^{\circ}$ dan motor dc kan mendorong kertas ke rak atas, dan sebaliknya ketika grade kertas kotor, maka servo akan menggerakan posisi $60^{\circ}$ dan Motor DC akan mendorong kertas ke rak bawah. Pembuktian penguji kertas didorong ke rak bawah terdapat pada Gambar dibawah ini: 


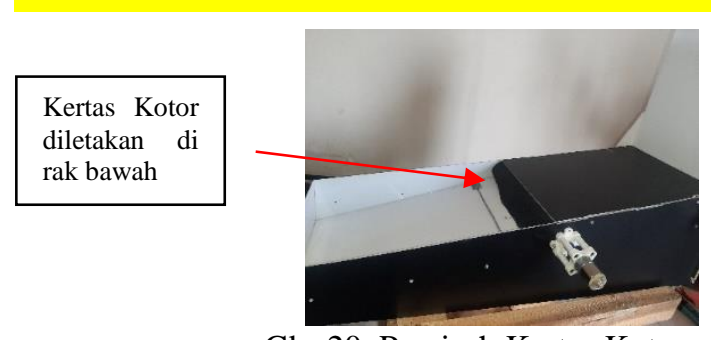

Gbr 20. Pemisah Kertas Kotor

\section{Pengujian Aplikasi Blynk pada Smartphone}

Pengujian dilakukan dengan cara menggunakan aplikasi blynk pada smartphone yang akan digunakan. Setelah melakukan login menggunakan e-mail dan password yang dibuat maka aplikasi dapat digunakan dengan tampilan yang sudah tersedia.

\subsubsection{Pengujian Koneksi Aplikasi Blynk dengan NodeMCU ESP8266}

Pada pengujian ini bertujuan untuk mengetahui kondisi ketika aplikasi blynk sudah terkoneksi dengan NodeMCU. Pengujian dilakukan dengan memberikan perintah running pada aplikasi blynk, jika pada simbol mikrokontroler tidak terdapat tanda merah maka aplikasi berhasil terkoneksi dengan NodeMCU.

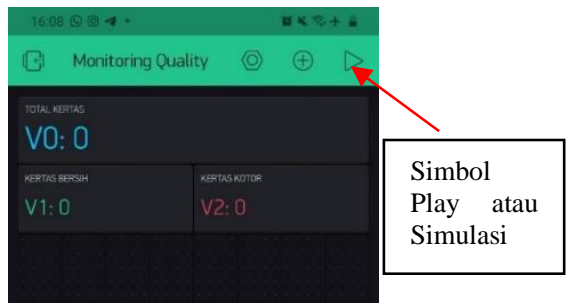

Gbr 21. Pengujian Koneksi Blynk dengan NodeMCU ESP 8266 Ketika Belum Terkoneksi

Pada Gambar diatas menunjukan bahwa aplikasi blynk belum terkoneksi dengan NodeMCU dikarenakan mesin belum dinyalakan atau belum menekan tombol simulasi. Gambar diatas menunjukan 3 widget display value untuk menampilkan hasil total kertas, kertas bersih dan kertas kotor.

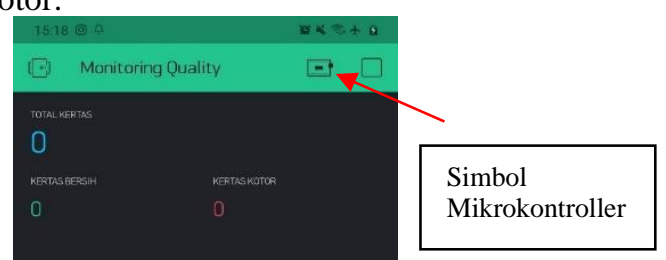

Gbr 22. Pengujian Koneksi Blynk dengan NodeMCU ESP 8266 Sudah Terkoneksi

Pada Gambar tersebut menunjukan bahwa aplikasi blynk sudah terkoneksi dengan NodeMCU hal ini ditandai dengan tidak adanya titik merah pada simbol mikrokontroler.

\subsubsection{Pengujian Widget Jumlah Kertas Pada Aplikasi Blynk}

Tujuan dari pengujian ini adalah untuk mengetahui hasil keluaran dari masing-masing widget value display untuk display jumlah kertas yang sudah diuji coba. Hasil pengujian ini dapat dilihat pada Tabel dibawah ini:
Tbl 4. Pengujian Widget jumlah Kertas pada Aplikasi Blynk

\begin{tabular}{ccccc}
\hline \multirow{2}{*}{$\begin{array}{c}\text { Jumlah } \\
\text { Kertas }\end{array}$} & $\begin{array}{c}\text { Jenis } \\
\text { Kualitas } \\
\text { Kertas }\end{array}$ & \multicolumn{2}{c}{$\begin{array}{c}\text { Jumlah Kertas yang Terbaca } \\
\text { pada Aplikasi Blynk } \\
\text { (Nilai Akumulasi) }\end{array}$} \\
\cline { 3 - 5 } & & $\begin{array}{c}\text { Total Kertas } \\
\text { Keseluruhan }\end{array}$ & $\begin{array}{c}\text { Kertas } \\
\text { Bersih }\end{array}$ & $\begin{array}{c}\text { Kertas } \\
\text { Kotor }\end{array}$ \\
\hline 1 & Bersih & 1 & 1 & 0 \\
\hline 2 & Kotor & 2 & 1 & 1 \\
\hline 3 & Bersih & 3 & 2 & 1 \\
\hline 4 & Kotor & 4 & 2 & 2 \\
\hline 5 & Bersih & 5 & 3 & 2 \\
\hline 6 & Kotor & 6 & 3 & 3 \\
\hline 7 & Bersih & 7 & 4 & 3 \\
\hline 8 & Kotor & 8 & 4 & 4 \\
\hline 9 & Bersih & 9 & 5 & 4 \\
\hline 10 & Kotor & 10 & 5 & 5 \\
\hline
\end{tabular}

Dari hasil pengujian widget jumlah kertas pada aplikasi blynk diatas menggunakan 10 kertas yaitu 5 kertas kotor dan 5 kertas bersih. Kertas tersebut telah melewati proses pemisah menggunakan aktuator motor servo MG855 maka hasil nilai akumulasi banyaknya kertas tersebut akan ditampilkan di aplikasi blynk. Pengujian dapat dibuktikan pada Gambar dibawah ini:

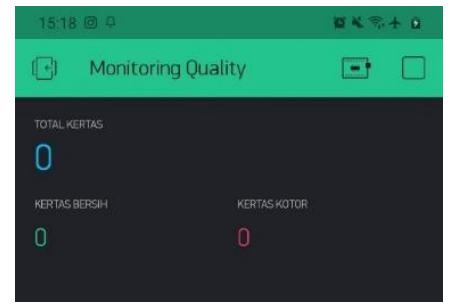

Gbr 23. Pengujian Kondisi Awal Aplikasi Blynk

Pada Gambar diatas merupakan pembuktian kondisi awal aplikasi blynk sebelum kertas dimasukan ke wadah kertas input. Setelah kertas dimasukan ke wadah atau tempat peletakan kertas input, maka akan mulai menghitung lembar kertas dengan menampilkan banyaknya total kertas yang disortir, kertas bersih maupun kertas kotor. Sebagai contoh yaitu dengan menggunakan 10 kertas diantaranya 5 kertas kotor dan 5 kertas bersih. Pembuktiannya terdapat dibawah ini:

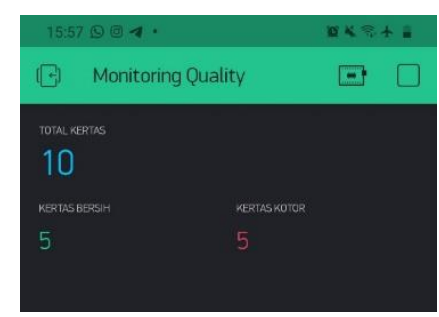

Gbr 24. Pengujian pada Aplikasi Blynk

Pada Gambar diatas dapat dilihat bahwa nilai yang ditampilkan pada widget adalah jumlah total kertas, jumlah kertas bersih dan jumlah kertas kotor yang sudah diuji sesuai dengan jumlah masukan kertas 10 buah, 5 kertas bersih dan 5 kertas kotor. 


\section{KESIMPULAN}

Kesimpulan yang bisa diambil dari pelaksanaan tugas akhir ini adalah :

1. Perancangan penarik kertas dengan letak kertas input yang diberdirikan dan diberikan sudut $30^{\circ}$ menggunakan motor dc sebagai roller sudah berfungsi dengan baik, sehingga mengatasi timbulnya permasalahan kertas double.

2. Ketika intenstas cahaya menembus diantara kertas dan sensor LDR, maka sensor LDR akan menerima nilai resistasnya, ketika nilai resistansi LDR kurang dari 75 maka akan dinyatakan kertas tersebut merupakan kertas layak pakai atau bersih dan sebaliknya, ketika nilai resistansi LDR lebih dari 75 maka akan dinyatakan kertas tersebut merupakan kertas tidak layak pakai atau kotor.

3. Hasil akhir dari sortir kertas yang ditampilkan ke aplikasi blynk sudah berfungsi dengan baik dan benar, sehingga operator dapat monitoring atau memantau kualitas kertas dengan jarak jauh.

\section{DAFTAR PUSTAKA}

[1] S. M. Cahyaningrum, "Kertas Test Liner Menggunakan Metode Failure Mode \& Effect Analysis ( FMEA ) ( Studi Kasus : PT Pura Barutama unit Paper Mill 9 ), 2017.

[2] R. Suwandahwana, "Perancangan Dan Pembuatan Alat Penghitung Jumlah Lembar Kertas Hasil Proses Cetak Skripsi," 2019.

[3] A. Istiadi, "Rancang Bangun Alat Penyortir Buah Tomat Berbasis Metode Jaringan Syaraf Tiruan Menggunakan Nodemcu Versi 1.0," Vol. 0, 2018.

[4] S. P. Tamba, A. H. M. Nasution, S. Indriani, N. Fadhilah, And C. Arifin, "Pengontrolan Lampu Jarak Jauh Dengan Nodemcu Menggunakan Blynk," J. Tek. Inf. Dan Komput., Vol. 2, No. 1, Pp. 93-98, 2019.

[5] S. Supatmi, "Pengaruh Ldr Terhadap Penontrolan Lampu" J. Teknik Komputer, Universitas Komputer Indonesia.

[6] T. U. Anastasia, A. Mufti Dan A. Rahman, "Rancang Bangun Sistem Parkir Otomatis Dan Informatif Berbasis Mikrokontroler Atmega2560" J. Tek. Elektro Dan Komputer, Universitas Syiah Kuala., Vol.2, No. 1, E-Issn: 2252-7036, 2017.

[7] S. Apriandi, M. Aminhd, Dan S. D. Asri, "Simulasi Pemilah Benda Berdasarkan Warna (Hitamputih) Menggunakan Sensor Warna Berbasis Mikrokontroler At89s51" J. Sistem Komputer, Stmik Indonesia., Vol.Ii (No.1), E-Issn: 2621-9840,

\section{9}

[8] E. Gunawan And A. B. Maulana, "Rancang Bangun Prototype Sistem Penyortiran Barang Melalui Kode Warna (Ourcode) Berbasis Arduino Uno," $J$. Cahaya Bagaskara, Vol. 1, No. 1, Pp. 22-29, 2017.

[9] P. Rahardjo, "Catu Daya Dc Tetap +5v Dan +12v/10a Untuk Laboratorium Elektronika" J. T.Elektronika Dan Komputer, Universitas Udayana, 2014.

[10] Arnita And M. Jasmanda, "Perancangan Sistem Komunikasi Data Dan Pengendalian Kecepatan Putaran Motor Dc", J. T.Elektronika, Universitas Bung Hatta Padang, Vol. 3, No.1, 2014.

[11] P. Andarrini, "Rancang Bangun Alat Penghitung Dan Pemilah Barang Menggunakan Sensor Warna Berbasis Mikrokontroler", J. Teknik Elektro, Politeknik Negeri Sriwijaya, 2017.

[12] F. Ramadhan, "Perancangan Penyortiran Barang Berdasarkan Berat Dengan Sistem Pick And Place Berbasis Mikrokontroler" J. Teknik Elektro, Universitas Negeri Padang, Vol.06, No.2, Issn: 2302-3309, 2020.

[13] R. A. A. Sancoko, E.Puspita, "Pendeteksi Embrio Dalam Telur Menggunakan Metode Image Processing", Department Of Electronic Engineering, Electronic Engineering Polytechnic Institute Of Surabaya Its Surabaya, Indonesia.

[14] Https://Datasheetspdf.Com/Datasheet/Mg995.Html (Diakses Pada 26 Agustus 2020)

[15] M. Zamroni, Drs. Moediyono, "Kendali Motor Dc Sebagai Penggerak Mekanik Pada Bracket LCD Proyektor dan Layar Dinding Berbasis Mikrokontroler AT89S51", Universitas Diponegoro Semarang.

\section{BIOGRAFI PENULIS}

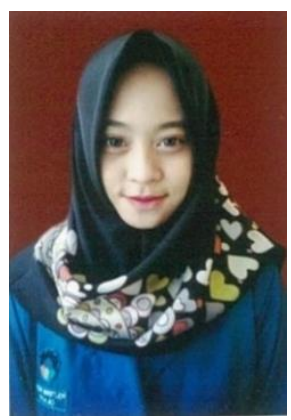

Hanna Alifia Putri Riyanto, Lahir di Cilacap Jawa Tengah, mahasiswa Politeknik Negeri Cilacap Program Studi D3 Teknik Elektronika. 